\title{
PENGARUH PENGGUNAAN MODEL PROBLEM BASED LEARNING TERHADAP KETERAMPILAN PASSING DALAM PERMAINAN FUTSAL
}

\author{
Beni Hamzah $^{1)}$, Oman Hadiana ${ }^{2)}$ \\ ${ }^{1}$ STKIP Muhammadiyah Kuningan \\ email: h.beni88@gmsil.com \\ ${ }^{2}$ STKIP Muhammadiyah Kuningan \\ email: hadianaoman@upmk.ac.id
}

\begin{tabular}{l} 
Info Artikel \\
\hline Sejarah Artikel: \\
Diterima Desember 2017 \\
Disetujui Desember 2017 \\
Dipublikasikan Januari 2018 \\
\hline Keywords: \\
Problem based learning, \\
keterampilan passing \\
futsal
\end{tabular}

\section{Abstrak}

Futsal merupakan olahraga yang dinamis dikarenakan bola bergulir secara cepat dari kaki ke kaki, dimana para pemainnya dituntut untuk selalu bergerak dan dibutuhkan keterampilan yang baik dan determinasi yang tinggi, dan tidak salah lagi futsal digemari akhir-akhir ini. Akan tetapi melihat dari karakteristik dari cabang olahraga futsal, Keterampilan dasar passing merupakan hal penting yang menghubungkan kelima pemain dalam satu unit yang berfungsi lebih baik daripada bagian-bagiannya. ketepatan, langkah, dan waktu pelepasan bola merupakan bagian yang penting dari kombinasi pengoperan bola yang berhasil. Berdasarkan uraian diatas penelitian ini bertujuan untuk mengetahui Apakah terdapat pengaruh model problem based learning terhadap keterampilan passing futsal, penelitian ini merupakan penelitian eksperimen, subjek dalam penelitian ini adalah siswa kelas XI IPA 1 di MAN 1 Kuningan dengan jumlah sampel 20. Hasil penelitian ini dapat disimpulkan bahwa Model Problem based learning berpengaruh signifikan terhadap keterampilan passing futsal siswa kelas XI IPA 1 MAN 1 Kuningan. dengan hasil diperoleh nilai $t_{\text {hitung }}$ sebesar 17.345 dengan sig $(0.000)$ dan nilai $t_{(d k: 50 \%)(20: 50 \%)}$ sebesar 1,72, maka $t_{\text {hitung }}>t_{\text {tabel }}$ atau sig (0.000) < a (0.05) maka hipotesis diterima. Artinya terdapat pengaruh yang positif dan signifikan terhadap pengaruh model problem based learning terhadap keterampilan passing bola futsal.

\begin{abstract}
Futsal is a dynamic sport because the ball is rolling rapidly from foot to foot, where the players are required to always move and they need good skills and high determination, and futsal is no doubt lately. But looking at the characteristics of the futsal sport, basic passing skills are important things that connect the five players in a unit that functions better than the parts. the accuracy, step, and time of releasing the ball are an important part of a successful ball pass combination. Based on the description above this study aims to find out whether there is an effect of the problem based learning model on futsal passing skills, this study is an experimental
\end{abstract}


study, the subjects in this study were students of class XI IPA 1 in MAN 1 Kuningan with a sample of 20. The results of this study can be concluded that the Model Problem based learning has a significant effect on the futsal passing skills of students of class XI IPA 1 MAN 1 Kuningan. with the results obtained tcount of 17,345 with sig $(0,000)$ and value $t_{(d k: 50 \%)}$ (20: 50\%) of 1.72, then tcount $>$ ttable or sig $(0.000)<(0.05)$ then the hypothesis is accepted. This means that there is a positive and significant influence on the effect of the problem based learning model on the passing skills of futsal balls.

(C) 2019 Beni Hamzah, Oman Hadiana Under the license CC BY-SA 4.0

Alamat korespondensi: ISSN 2443-1117 (cetak)

E-mail : : hadianaoman@upmk.ac.id

No Handphone : 08562025609 


\section{PENDAHULUAN}

Pendidikan Jasmani seringkali
terkalahkan oleh pendidikan akademik
lainnya, padahal aspek kesehatan jasmani
merupakan aspek penting guna mendukung
pendidikan akademik di sekolah.
Sebagaimana diketahui bersama bahwa di
dalam tubuh yang sehat terdapat jiwa yang
kuat, implikasinya jika tubuh dan pikiran
sehat maka siswa pun mudah menyerap
pelajaran yang disampaikan oleh guru.
Proses pendidikan yang memanfaatkan
aktivitas jasmani ini memang telah
dirancang secara sistematik guna
mengembangkan dan meningkatkan
individu secara organik, neuromuskuler,
perseptual, kognitif dan emosional, dalam
kerangka sistem pendidikan nasional
(Depdiknas, 2003:6).
Pendidikan jasmani terdapat beragam metode pembelajaran yang dapat digunakan untuk menyampaikan beragam materi pendidikan jasmani termasuk olahraga permainan. Olahraga permainan itu sendiri terdiri dari permainan individu dan permainan beregu. Pembelajaran Pendidikan jasmani yang mengutamakan permainan beregu diantaranya adalah permainan bola futrsal. Permainan futsal sangat cocok untuk para siswa di sekolah, karena gerak yang dilakukan pada permainan futsal dapat efektif guna merangsang pertumbuhan anak.

Futsal merupakan salah satu cabang olahraga permainan yang dimainkan oleh dua regu yang masing-masing regu terdiri dari 5 orang pemain yang salah satunya adalah penjaga gawang. Cabang olahraga ini asal mulanya dari cabang olahraga sepakbola yang lebih disederhanakan. Ukuran lapangan dan bola yang digunakan lebih kecil dibandingkan sepakbola. Begitu juga dengan peraturan permainan yang berbeda. Aturan permainan futsal dengan sengaja dibuat sangat ketat oleh FIFA agar nilai Fair Play terjadi dan sekaligus untuk menghindari cedera berhubung lapangan permainan futsal (untuk pertandingan internasional) bukan terbuat dari rumput, tetapi dari kayu atau pelastik/rubber, sehingga apabila terjadi benturan akan sangat berbahaya bagi para pemain.

Dalam dunia pendidikan cabang olahraga futsal selain masuk dalam mata pelajaran permainan bola besar, kegiatan ini juga merupakan ekstrakurikuler yang sering diberlakukan oleh setiap sekolah. Kegiatan ini juga bermanfaat untuk melihat potensi dan bakat yang dimiliki oleh peserta didik.

Berdasarkan hal tersebut, guru perlu merancang pembelajaran yang mampu membangkitkan potensi siswa dalam menggunakan kemampuan berpikirnya untuk menyelesaikan masalah. Salah satu pendekatan pembelajaran tersebut adalah apa yang disebut "Pembelajaran Berbasis Masalah (PBM)" atau "Problem Based Learning (PBL)". Pendekatan pembelajaran ini dipusatkan kepada masalah-masalah yang disajikan oleh guru dan siswa menyelesaikan masalah tersebut dengan seluruh pengetahuan dan keterampilan mereka dari berbagai sumber yang dapat diperoleh. guru sebaiknya membangkitkan motivasi belajar siswa agar siswa berpartisipasi aktif dalam pembelajaran ekstrakurikuler futsal. Dalam meningkatkan motivasi belajar futsal dapat dilakukan dengan model pembelajaran berbasis masalah atau problem based learning (PBL). Sebab menurut Schunk Pintrich \& Meece (Paul Eggen \& Donald Kauchak, 2012: 346) PBL bisa efektif meningkatkan motivasi siswa karena memanfaatkan efek rasa ingin tahu, tantangan, tugas autentik, dan keterlibatan.

Permainan futsal dapat berlangsung lancar, teratur dan menarik apabila pemain menguasai unsur-unsur dalam permainan futsal adalah penguasaan teknik dasar. Teknik dasar yang harus dikuasai oleh pemain futsal salah satunya adalah passing. Passing tujuannya untuk memberikan atau mengoper bola kepada teman. Passing yang baik dan benar sangat dibutuhkan dalam bermain futsal, karena dengan menguasai teknik ini maka akan mempermudah teman kita untuk menerima bola. Untuk penguasaan passing, diperlukan penguasaan gerakan sehingga sasaran yang diinginkan tercapai. 
Masalah yang diperoleh dari hasil wawancara salah satunya adalah kesulitan siswa dalam memahami keterampilan passing. keterampilan passing merupakan teknik dasar yang cukup susah untuk dikuasai siswa, sehingga dibutuhkan pembelajaran yang inovatif. Pembelajaran dan latihan inovatif diharapkan mampu meningkatkan kemampuan passing siswa dalam pembelajaran futsal. Teknik dasar passing dapat dilakukan dengan beberapa pola latihan. Akan tetapi siswa membutuhkan pola latihan yang menarik dan mudah dimengerti.

Berdasarkan permasalahan yang terjadi di atas dapat ditarik kesimpulan bahwa penting untuk mengetahui seberapa besar keterampilan passing bermain futsal dengan melakukan penelitian model problem based learning.

\section{METODE PENELITIAN}

Metode penelitian yang digunakan penulis untuk menguji kebenaran hipotesis yang telah diajukan adalah metode eksperimen. Desain Penelitian berfungsi untuk memberikan jalan dan arah proses penelitian yang dilakukan. Mengenai definisi penelitian ini Nasution (2004:40) menyatakan bahwa: "Desain Penelitian merupakan suatu rencana tentang cara mengumpulkan dan menganalisis data sesuai dengan tujuan penelitian". Dalam penelitian ini desain penelitian yang digunakan adalah One Group Pre-test and Post-test Design. Sugiyono (2009:5). Populasi pada penelitian ini adalah siswa kelas XI IPA 1 MAN 1 Kuningan dengan jumlah 40 siswa. Sedangkan sampel penelitian sebanyak 20 siswa laki-laki, dan teknik pengambilan sampel menggunakan purposive sampling. Sesuai dengan pendapat Sugiyono (2009: 82) mengatakan bahwa "teknik Purposive sampling digunakan untuk menentukan sampel penelitian dengan beberapa pertimbangan tertentu yang bertujuan agar data yang diperoleh bisa lebih representatif". Instrumen penelitian menggunakan adalah tes passing and stopping sepakbola. (Nurhasan, 2007:207). Teknik analisis data yang digunakan dalam penelitian: 1) Uji prasyarat analisis: a. uji normalitas b. uji homogenitas. 2) Uji hipotesis menggunakan uji-t (t-test).

Gambar 1 Rancangan Penelitian

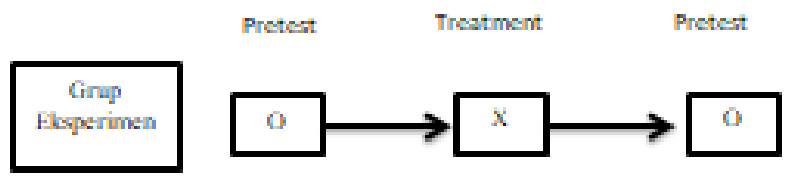

\section{HASIL DAN PEMBAHASAN}

Untuk memperoleh informasi tentang gambaran penggunaan model problem based learning terhadap keterampilan passing dalam permainan bola futsal siswa MAN 1 Kuningan, penelitian ini melakukan tes awal (pretest) dan (posttes) dengan cara

Tabel 1 Data Hasil Pretest dan Postest keterampilan Passing Bola Futsal

\begin{tabular}{cccccc}
\hline & & Mean & $\mathrm{N}$ & Std. Deviation & Std. Error Mean \\
Pair 1 & Pretest & 9.60 & 20 & 2.624 & .587 \\
\cline { 2 - 6 } & Posttest & 14.55 & 20 & 2.625 & .587 \\
\hline
\end{tabular}

sekor yang diperoleh taste menyepak dan menahan bola yang sah selama 30 detik dengan instrumen "keterampilan passing futsal". Adapun hasil tes keterampilan passing dalam permainan bola futsal siswa MAN 1 Kuningan dapat dilihat pada tabel 4.1. 
Berdasarkan tabel 4.1 menjelaskan bahwa dari 20 siswa, hasil tes kemampuan keterampilan passing dalam permainan futsal pada siswa kelas XI IPA I MAN 1 Kuningan hanya mampu melakukan passing sebanyak $9.60 \mathrm{kali} / \mathrm{menit}$ dengan standar deviasi 2.624. sedangakan setelah menerapakan model problem based learning terhadap keterampilan passing dalam permainan bola futsal rata-rata keterampilan passing bola futsal sebesar $14.55 \mathrm{kali} / \mathrm{menit}$ dengan standar deviasi sebesar 2.625. artinya setelah menerapakan model Problem based learning terhadap keterampilan passing dalam permainan bola futsal mengalami penikatan sebesar 6 kali/menit yaitu dari $9.60 \mathrm{kali} / \mathrm{menit}$ menjadi $2.624 \mathrm{kali} / \mathrm{menit}$.
Data penelitian yang telah diambil diuji terlebih dahulu untuk mengetahui karakteristik dari data tersebut. Salah satu jenis pengujian yang harus dilakukan adalah uji normalitas data. Tujuan digunakan uji normalitas adalah untuk mengetahui apakah data yang diperoleh darikegiatan penelitian menmpunyai distribusi (sebaran) yang normal atau tidak.

Jika distribusi (sebaran) data normal, maka rumus uji hipotesis yang digunakan adalah jenis uji yang termasuk ke dalam statistik parametrik, dan jika data tidak berdistribusi normal maka maka menggunakan statistik non parametrik.

Adapun pengujian normalitas data dilakukan dengan menggunakan batuan SPSS For Windows versi 20, hasil dapat dilihat pada tabel berikut:

\begin{tabular}{|c|c|c|c|c|c|c|}
\hline \multicolumn{7}{|c|}{ Tabel 2 Tests of Normality } \\
\hline & \multicolumn{3}{|c|}{ Kolmogorov-Smirnov $^{\mathrm{a}}$} & \multicolumn{3}{|c|}{ Shapiro-Wilk } \\
\hline & Statistic & Df & Sig. & Statistic & Df & Sig. \\
\hline Pretest & .129 & & $.200^{*}$ & .975 & & .855 \\
\hline
\end{tabular}

Jika nilai sig > $a 0,05$ maka data berdistribusi normal

Jika nilai $<a 0.05$ maka data tidak berdistribusi normal

Berdasarkan data di atas, maka diperoleh nilai sig. sebesar 0.200 maka sig $(0,200)>a(0,05)$, maka hipotesis diterima artinya data pretest passing bola futsal memiliki persebaran data berdistribusi normal. Untuk lebih jelasnya persebaran data dapat dilihat pada gambar berikut:

\section{Gambar 2 Diagaram Plot Uji Normalitas Data Pretest Passing Bola Futsal}




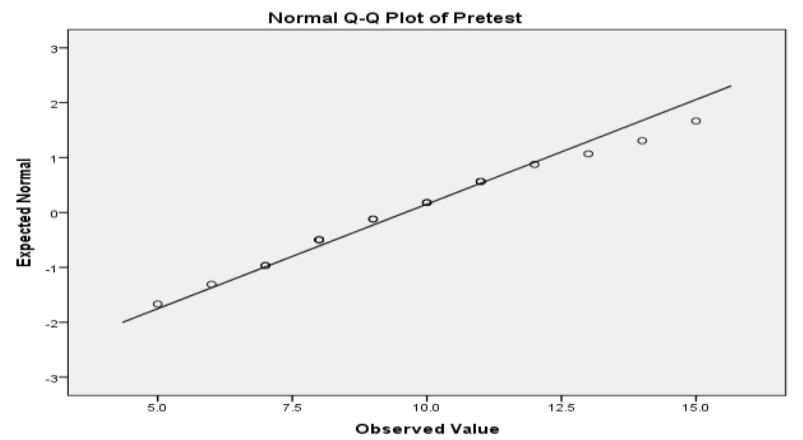

Berdasarkan hasil pengujian persyarat dengan uji normalitas data berdistribusi normal dan diambil dari data yang homogen. Sehingga pengujian hipotesis dalam penelitian ini dilakukan dengan menggunakan uji t. Adapun penggujian pada setiap hipotesis.

Untuk memperoleh jawaban terhadap rumusan masalah maka peneliti menganalisis data dan uji normalitas, uji homogenitas dan uji hipotesis dengan uji t. Berdasarkan perhitungan sebelumnnya diperoleh bahwa data pretest dan posttest dengan penerapan penggunaan model problem based learning terhadap keterampilan passing dalam permainan bola futsal memiliki data yang berdistribusi normal dan diambil dari sempel yang homogen, maka penggujian hipotesis dilakukan dengan uji statistik parametric uji t. Adapun hipotesis yang diajukan adalah "terdapat pengaruh model problem based learning terhadap keterampilan passing futsal siswa kelas xi man 1 kuningan". Tabel 4.5 Tabel Uji $t$

\begin{tabular}{|c|c|c|c|c|c|c|c|c|c|}
\hline & & \multicolumn{5}{|c|}{ Paired Differences } & \multirow[t]{3}{*}{$\mathrm{T}$} & \multirow[t]{3}{*}{$\mathrm{df}$} & \multirow{3}{*}{$\begin{array}{l}\text { Sig. }(2- \\
\text { tailed) }\end{array}$} \\
\hline & & \multirow[t]{2}{*}{ Mean } & \multirow[t]{2}{*}{$\begin{array}{l}\text { Std. } \\
\text { Deviati } \\
\text { on }\end{array}$} & \multirow[t]{2}{*}{$\begin{array}{l}\text { Std. Error } \\
\text { Mean }\end{array}$} & \multicolumn{2}{|c|}{$\begin{array}{l}\text { 95\% Confidence } \\
\text { Interval of the } \\
\text { Difference }\end{array}$} & & & \\
\hline & & & & & Lower & Upper & & & \\
\hline $\begin{array}{r}\text { Pair } \\
1\end{array}$ & $\begin{array}{c}\text { Posttest - } \\
\text { Pretes }\end{array}$ & 4.950 & 1.276 & .285 & 4.353 & 5.547 & 17.345 & 19 & .000 \\
\hline
\end{tabular}

Berdasarkan hasil perhitungan di atas diperoleh nilai $t_{\text {hitung }}$ sebesar 17.345 dengan sig (0.000) dan nilai $\mathrm{t}_{(\mathrm{dk}: 50 \%)(20: 50 \%)}$ sebesar 1,72, maka $t_{\text {hitung }}>t_{\text {tabel }}$ atau sig $(0.000)<a(0.05)$ maka hipotesis diterima. Artinya terdapat pengaruh yang positif dan signifikan terhadap pengaruh model problem based learning terhadap keterampilan passing futsal siswa kelas xi ipa 1 man 1 kuningan.

Penelitian bertujuan untuk mengetahui pengaruh penggunaan model problem based learning terhadap keterampilan passing dalam permainan bola futsal siswa man 1 kuningan. Untuk melihat perbedaan pengaruh penggunaan model problem based learning terhadap keterampilan passing dalam permainan bola futsal siswa man 1 kuningan.

Hasil perhitungan dengan menggunakan uji $\mathrm{t}$ diproleh nilai $\mathrm{t}_{\text {hitung }}$ sebesar 17.345 dengan sig $(0.000)$ dan nilai $t$ (dk:50\%)(20:50\%) sebesar 1,72, maka $\mathrm{t}_{\text {hitung }}>\mathrm{t}_{\text {tabel }}$ atau sig $(0.000)<a(0.05)$ maka hipotesis diterima. Artinya terdapat pengaruh yang positif dan signifikan terhadap pengaruh model problem based learning terhadap keterampilan passing bola futsal siswa kelas xi ipa 1 man 1 kuningan.

Berkaitan dengan data penelitian diatas, dapat disimpulkan bahwa penerapan 
model problem based learning terhadap keterampilan passing bola futsal berpengaruh terhadap passing bola futsal sehingga ada perbedaan jika dibandingkan sebelum melakukan penerapan model problem based learning.

\section{SIMPULAN}

Berdasarkan hasil dan pembahasan penelitian yang telah diuraikan pada bab sebelumnya, peneliti menarik kesimpulan bahwa "model problem based learning berpengaruh signifikan terhadap keterampilan passing dalam permainan futsal pada siswa kelas xi ipa 1 man 1 kuningan."

\section{DAFTAR PUSTAKA}

Arends, Richard.(2008). Learning to Teach: Belajar untuk Mengajar. Yogyakarta Pustaka Pelajar.

C. Asri Budiningsih. (2006). Strategi Pembelajaran. Yogyakarta: FIP UNY.

Jakarta: Departemen Pendidikan dan Kebudayaan Direktorat Jenderal Pendidikan Tinggi Proyek Pengembangan Lembaga Pendidikan Tenaga Kependidikan.

Justinus Lhaksana Ishak H. Pardosi.(2008) .Inspirasi dan Spirit Futsal. Jakarta.

Jumhana, J., \& Agustan, B. (2016). Pengaruh Model Directinstruction Terhadap Teknik Dasar Dribbling Dalam Permainan Sepak Bola. JUARA : Jurnal Olahraga, 1(1), 4650. doi:10.33222/juara.v1i1.57

Justinus Lhaksana.(2012) .Taktik dan Strategi Futsal modern.Depok: Be Champion.
Komarudin. (2005). Diktat Pembelajaran Dasar Gerak Sepakbola. Yogyakarta: Program Studi Pendidikan Jasmani Kesehatan dan Rekreasi. Jurusan Pendidikan Olahraga. FIK UNY

Murhananto.(2006). Dasar-dasar Permainan Futsal (Sesuai dengan Peraturan FIFA). Jakarta: PT. Kawan Pustaka.

Nanang Riyadi. (2013). Tingkat Keterampilan Kemampuan Dasar Bermain Futsal yang Menggunakan Lapangan Agung Futsal Jatianom Klaten.Skripsi. Yogyakarta: FIK UNY.

Nurhasan. (2001). Tes dan pengukuran Dalam Pendidikan Jasmani: Prinsip-Prinsip dan Penerapannya. Jakarta: Depdiknas.

Ramadan, G. (2017). Pengaruh Metode Pembelajaran Dan Motivasi Belajar Terhadap Hasil Belajar Passing Sepakbola. JUARA : Jurnal Olahraga, 2(1), 1-10. doi:10.33222/juara.v2i1.27

Rusman. (2011). Model-model Pembelajaran Mengembangkan Profesionalisme Guru. Jakarta: Rajawali Press.

Rusmono. (2012). Strategi Pembelajaran dengan Problem based Learning Itu Perlu untuk meningkatkan profesionalitas Guru. Bogor: Ghalia Indonesia.

Sahda Halim. (2009) .1 hari pintar main futsal.Yogyakarta: Penerbit Media presindo. 